\title{
A Novel Idea for Self-Balancing Car Parks for Plug in Electric Vehicle Charging
}

\author{
Andrew D. Clarke, Elham B. Makram \\ Department of Electrical and Computer Engineering, Clemson University, Clemson, USA \\ Email: adclark@g.clemson.edu, makram@clemson.edu
}

Received 10 September 2014; revised 7 October 2014; accepted 21 October 2014

Copyright (C) 2014 by authors and Scientific Research Publishing Inc.

This work is licensed under the Creative Commons Attribution International License (CC BY). http://creativecommons.org/licenses/by/4.0/

c) (i) Open Access

\begin{abstract}
Many existing studies seek to examine and mitigate possible impacts which plug in vehicle (PEV) charging will have on electric utilities. As PEVs increase in popularity, car parks will have to be built in order to allow for charging while away from home. Existing studies fail to consider the unbalance conditions in the distribution feeders to car parks during PEV charging. This paper presents an innovative idea to improve the unbalance conditions caused by a car park by reconfiguring PEV charger connections to a three-phase system. Although the developed algorithm is simple, results show its ability to balance the power among the phases. A car park is used as an example to show that balancing of the real power drawn by PEV chargers in a parking structure is a success.
\end{abstract}

Keywords

Unbalance, Electric Vehicles, Power System Control, Smart Grid

\section{Introduction}

Some forecasts predict that plug in electric vehicles (PEVs) will account for nearly one third of all new vehicle purchases by 2020 [1]. PEVs can be further classified as plug in hybrid electric vehicles (PHEVs), battery electric vehicles (BEVs), and extended range electric vehicles (EREVs). PHEVs and EREVs have both an electric drivetrain as well as an internal combustion engine while BEVs have only an electric drivetrain [2]. With the steadily increasing popularity of PEVs, charging infrastructure is needed to allow owners the security of being able to recharge when it becomes necessary, especially in the case of BEVs, where the vehicle has no propulsion source once the battery is depleted. PEV owners are therefore expected to desire charging stations installed both at home as well as large car parks located at commercial buildings.

In large commercial car parks, due to the number of PEV chargers that will be present, it is expected that power will be fed from a three-phase distribution system. AC PEV chargers are typically divided into three le- 
vels, shown in Table 1 [3]. Currently available PEV chargers fall into the classification of the standardized levels 1 and 2 [4]. Due to the higher energy transfer capability of level 2 chargers compared to level 1, which corresponds to a shorter charge time, it is expected PEV owners will desire these chargers if available.

Many existing studies attempt to examine the effects of PEVs on a distribution system. These studies focus primarily on transformer overheating, system overloading, and ancillary services that can be provided through vehicle to grid (V2G) [5]-[9]. Existing studies fail to consider the problem of power unbalance in the distribution system however. In distribution systems, balancing of power between phases is attempted by distributing single phase loads equally between the three phases. In a car park, it is expected that one third of the chargers will be connected to each phase in order to attempt balancing. With varying loads due to individual PEV charging rates and intermittent loads from vehicles connecting and disconnecting, this becomes impossible using a static phase connection with single phase PEV chargers however. It is very likely that a PEV car park will therefore exacerbate the unbalance conditions that already present in most distribution systems by drawing uneven power from each phase.

These conditions may be harmful to the distribution system due to zero and negative sequence currents that flow in the system when unbalance is present. Unbalanced conditions lead to higher losses, higher temperatures in transformers and motors, diminished power transfer limits of devices, and the potential to inhibit correct protection device operation [10] [11]. The goal of this work is to expand on work in [12] and present an idea that can significantly decrease or eliminate unbalanced operation of a car park by balancing real power. In this work, the idea is to actively change the phase that each PEV charger is connected to in order to balance the power drawn from the distribution system by the car park.

This paper is organized in the following sections: Section 2 details the model used to represent each PEV; Section 3 has a description of the self-balancing car park; Section 4 contains the results of a simulation run with a sample algorithm to show the potential of using PEVs for balancing; and Section 5 has the final conclusion of the paper.

\section{PEV Charger Model}

PEV chargers typically consist of an AC-DC converter followed by a DC-DC converter. The AC-DC converter is responsible for the interaction of the charger with the electric grid and the DC-DC converter is responsible for ensuring the battery is charged according to a constant current and constant voltage profile [13] [14]. One control topology that can be used to control the PEV charger's AC-DC converter is current control. In this method of control, the current flowing into the charger is directly controlled [13]. It is shown in [15] that a single phase PEV charger can be developed that will accurately draw or supply a commanded real power based on this control methodology. A controlled current source is therefore used to model each PEV charger in place of the full detailed model. The required current can be calculated based on Equation (1) by using the measured voltage at the terminal of each PEV charger and the desired real and reactive powers. Based on the limits prescribed by standardized level 1 and 2 chargers, the real power is limited to a maximum of $7 \mathrm{~kW}$ per PEV [3].

$$
I_{\text {peak }}=\frac{2(P+j Q)^{*}}{V_{\text {peak }}^{*}}
$$

\section{Self-Balancing Car Park}

The goal of this paper is to present the idea of moving PEV chargers between phases automatically to balance a car park and show the viability of using such a scheme in a realistic example of a car park. This idea works by

Table 1. PEV charging levels [3].
\begin{tabular}{cccc}
\hline Charging level & Nominal supply voltage & Maximum current & Continuous input power \\
\hline 1 & $120 \mathrm{~V}, 1$ phase & $12 \mathrm{~A}$ & $1.44 \mathrm{~kW}$ \\
2 & $208-240 \mathrm{~V}, 1$ phase & $32 \mathrm{~A}$ & $6.66-7.68 \mathrm{~kW}$ \\
3 & $208-600 \mathrm{~V}, 3$ phase & $400 \mathrm{~A}$ & $>7.68 \mathrm{~kW}$ \\
\hline
\end{tabular}


moving PEVs drawing power from heavily loaded phases to lightly loaded phases and doing the opposite for PEVs supplying power through V2G. This has the effect of increasing the power drawn by the lightly loaded phase while simultaneously reducing the power drawn by the heavily loaded phase. Because PEV charging rates are not altered using this idea, PEV charging is allowed to continue in almost the same way as with a static phase connection. The impact on PEV owners is therefore expected to be unnoticeable, while the overall car park is expected to have less impact on the distribution system than an equivalent car park without phase balancing present. In order to be successful, each PEV must have the ability to switch between all three phases. This is accomplished by adding a switching element between the terminals of the PEV charger and the distribution grid. In this study, single phase breakers are used, however power electronic solid state switches or any other switch that allows disconnection from one phase and connection to another could also be used for this purpose. To illustrate the feasibility of this idea, a sample heuristic algorithm that requires minimal computations is developed and used to control the phase each PEV charger is connected to.

The algorithm works by first receiving data on how much power each PEV charger is currently drawing or supplying. It then checks to see if a predefined time has passed since the last placement of vehicles. For this study, the time was chosen as 10 seconds. This time represents the minimum time between switching a vehicle from one phase to another. By decreasing the time, the algorithm is able to operate faster to keep up with changing PEV loads. Wear on switching elements will be increased however. By increasing the time, wear on switching elements will be reduced. The algorithm will wait longer to adapt to changing PEV loads and will require a vehicle to wait longer upon plugging in before charging is allowed to commence.

After this time delay has passed since the last calculation, the algorithm checks if any vehicles have been connected or disconnected or if any vehicle charging rates have changed since the last calculation. If none of these have happened, the calculation time is stored and the algorithm exits and waits for the time delay again before resuming. No PEV chargers are moved between phases in this scenario. If at least one of these has happened however, the algorithm continues calculating a new assignment. The PEV charger powers are first sorted into a list from largest to smallest by absolute value. The initial power on each phase is considered to be $0 \mathrm{~W}$. The list is then stepped thorough one entry at a time, starting with the first PEV charger in the list, which corresponds to the PEV charger with the maximum absolute value of power. The PEV charger is checked to see if it is drawing or supplying power. If it is drawing power, it will be assigned to the phase drawing the minimum power. If it is supplying power, it will be assigned to the phase drawing the maximum power. If it is doing neither, it will be assigned to disconnect from all three phases. If two phases or more phases are drawing the same power, the priority of the equal phases, is phase $\mathrm{A}$, phase $\mathrm{B}$, and finally phase $\mathrm{C}$. The new power on each phase is recalculated using Equation (2) based on the assignment. The assignment continues until all PEV chargers have been assigned a phase or commanded to disconnect. After all assignments are complete, the switching commands are sent and the PEV chargers automatically switch to the assigned phase. A graphical representation of the algorithm can be found in Figure 1.

$$
P_{\text {Phase }}=\sum_{x \in \text { Phase }} P_{\mathrm{PEV}}(x)
$$

\section{Results}

To test the sample algorithm, it is applied to a simulated car park containing 300 level 2 PEV chargers and different scenarios are tested to show its operation and the feasibility of this idea. For the first half of all scenarios, balancing using PEVs does not occur and represents a traditional car park with static phase connections. One third of all chargers are connected to each phase. Balancing is then allowed using PEVs and the new powers drawn from each phase are shown. The first scenario represents the most extreme case possible. It is extremely unlikely to occur, however it is possible. In this case, a total of 100 PEVs are each connected to a charger and all PEVs are considered to have parked at a charger connected to phase A while drawing the maximum power of 7 kW. Figure 2 shows that before PEV balancing occurs, the power drawn by the car park is extremely unbalanced and will likely have negative effects on the distribution system supplying power to it. After PEV balancing occurs however, the power drawn by the car park very close to balanced. This is because vehicles are switched from phase A to phases B and C. It should be noted that the power on phase A remains slightly higher than phases B and C because after all phases have an equal number of PEV chargers assigned to them, there is still one remaining to be assigned and based on the priority described earlier, it is placed on phase A. Also, the 


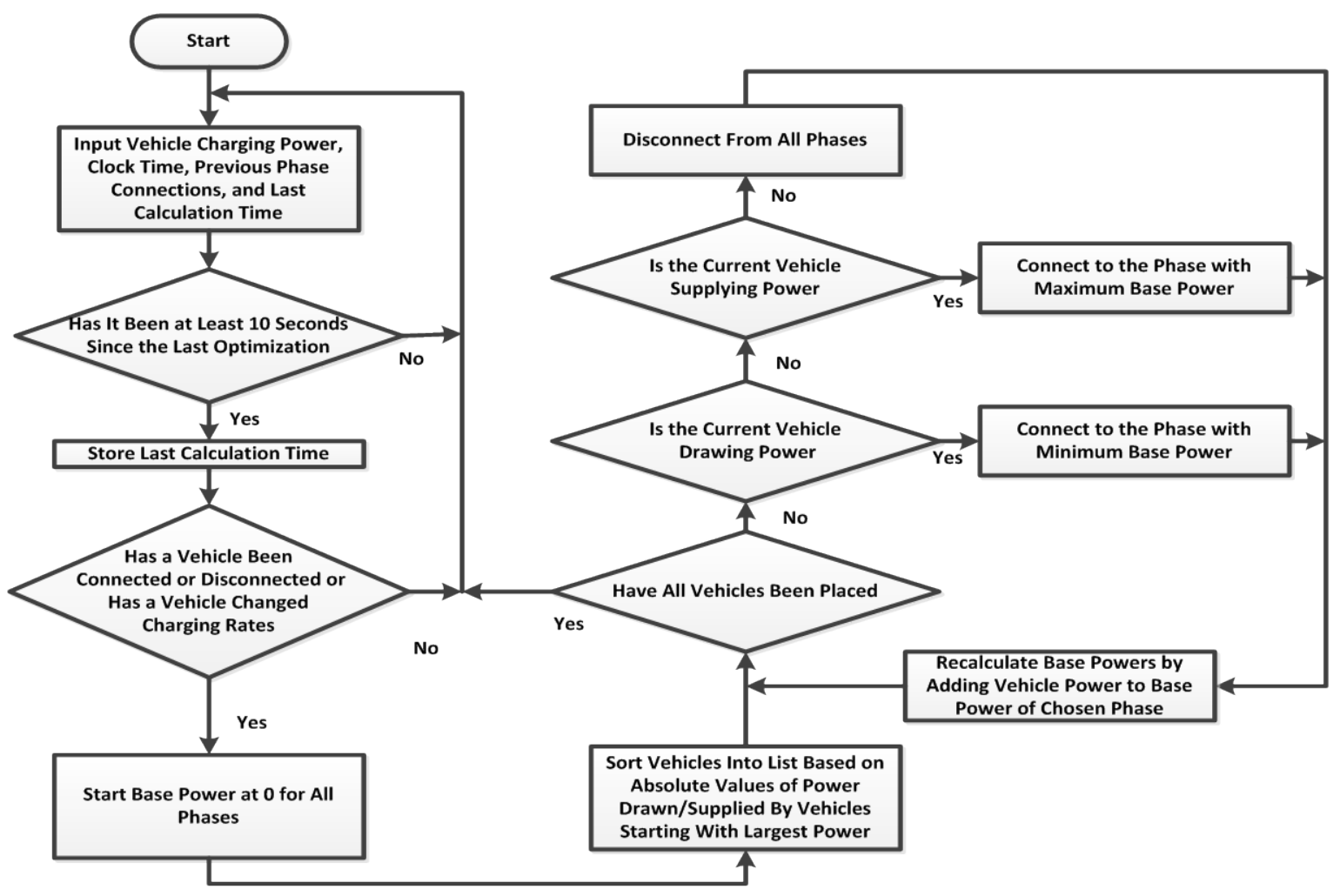

Figure 1. Self-balancing car park algorithm.

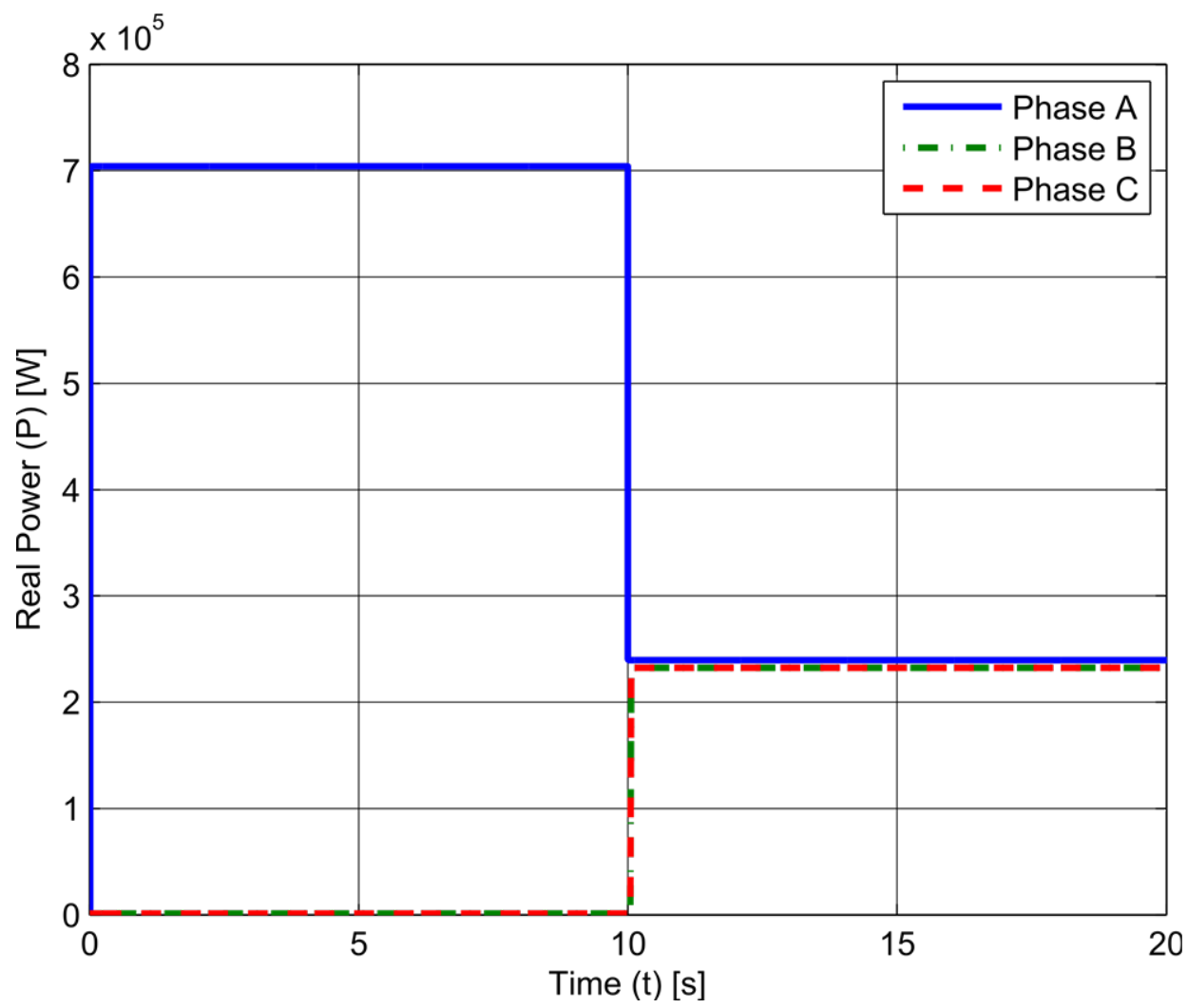

Figure 2. Results from first scenario. 
power for phases $\mathrm{B}$ and $\mathrm{C}$ is the same so the lines overlap in this figure.

Another scenario is conducted in which all 300 PEV charger powers are chosen using a pseudorandom function in MATLAB. In this case, the initial period before balancing begins shows the powers of the three phases are closer to balanced however unbalance still exists. After the initial 10 seconds of unbalance conditions, PEVs are used for balancing and the power between phases becomes closely matched. Figure 3 shows the results. It should be noted that there is a transient seen during the switching, as would be expected based on the instantaneous changes of the simple switching devices and current sources used in this paper, however because it is not of interest for showing the feasibility of this idea, the full magnitude is not shown.

In order to be practical in a real world car park, the balancing must be able to keep up with reconfiguration of the PEV load in the car park. As PEVs are plugged in or unplugged from chargers, the power drawn from the chargers will change. When this happens, the PEV chargers that are drawing power must be reconfigured to rebalance the power drawn by the car park. A third scenario is conducted where PEV charger powers are changed half way through the simulation. Figure 4 shows the results of a changing load. The first 20 seconds of Figure 4 is the same as shown in Figure 3. At 20.05 seconds, all PEV charger powers are again assigned using a pseudorandom function in MATLAB. The phase each PEV charger is connected to is not changed until 30 seconds however due to the 10 second delay between assignments. During this short period, new PEVs that are connected to the system will not begin to charge because the charger was previously disconnected from all phases. At 30 seconds, the balancing algorithm runs again and the assignments are updated. The powers of the three phases again approach balanced conditions.

\section{Conclusion}

Even with the implementation in this paper, which is accomplished through a simple heuristic algorithm that requires minimal computational power, the presented innovative idea is shown to be a viable way to mitigate

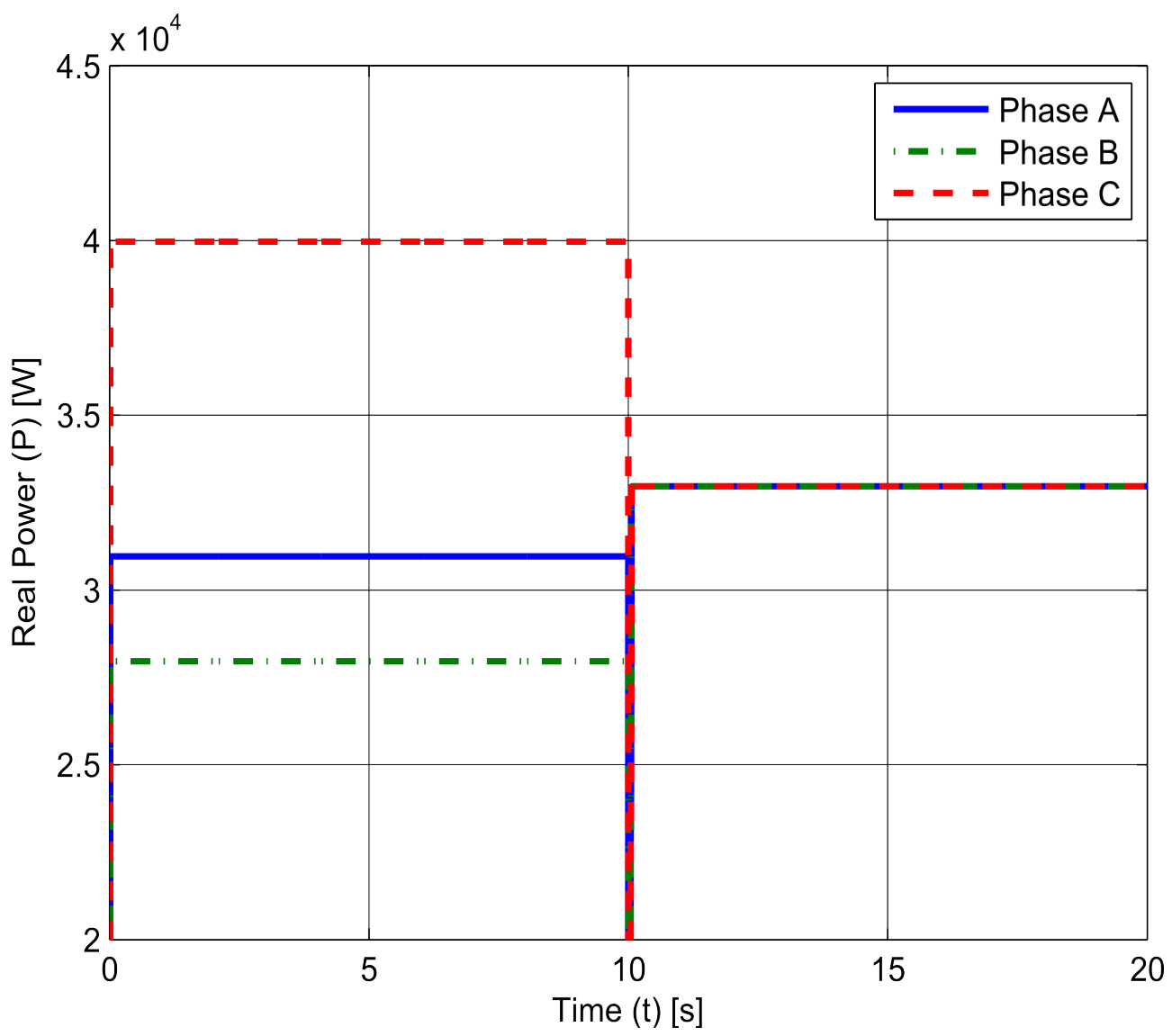

Figure 3. Results from second scenario. 


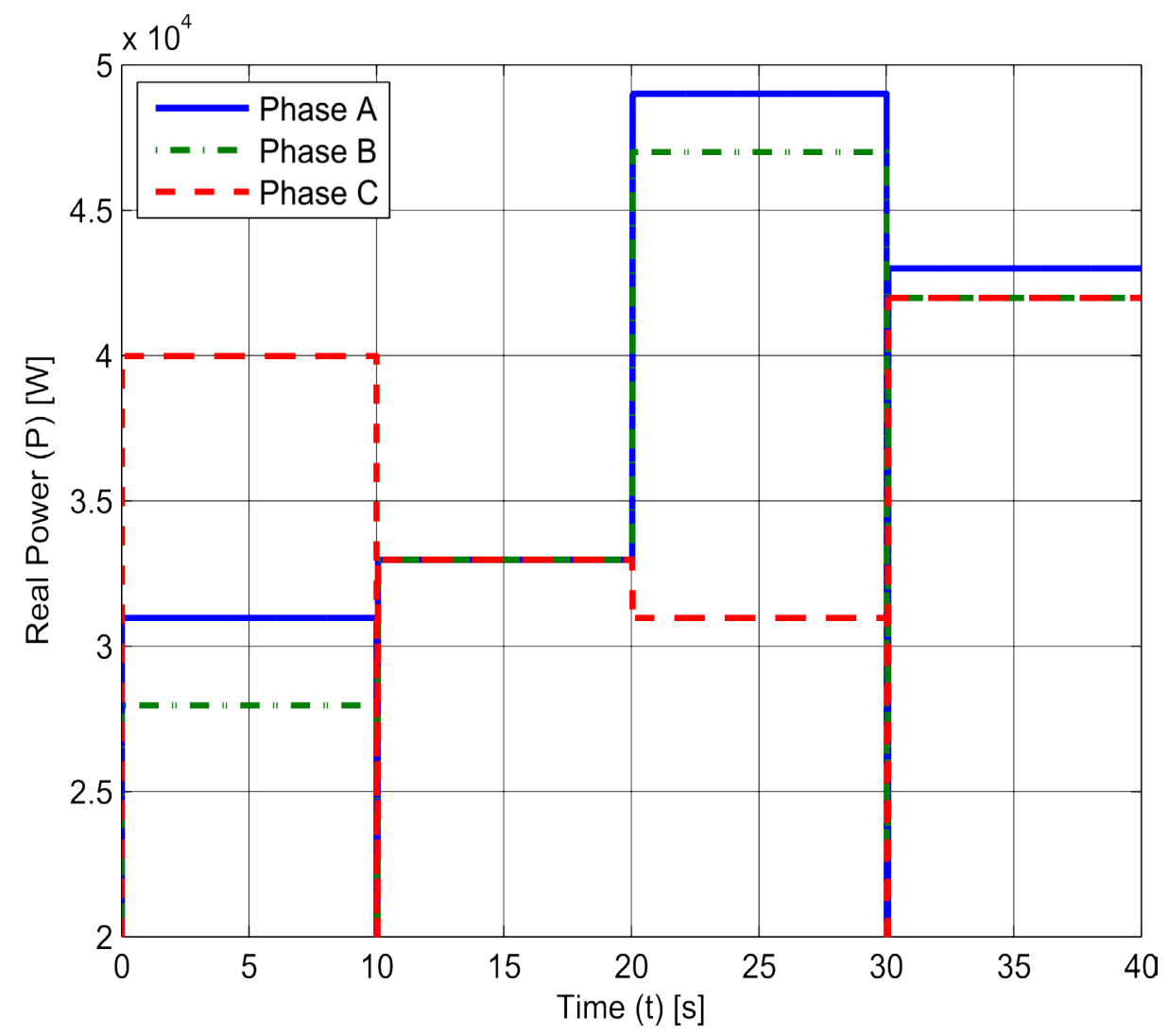

Figure 4. Results from third scenario.

unbalance in a PEV car park. It can be seen that by applying this method of moving PEV chargers between phases based on the current PEV car park configuration, balancing can be accomplished. Also, as the availability of PEVs in a car park changes, it is shown that balancing remains feasible by reassigning PEV charger phases after the change in PEV connections. By balancing the power drawn from each phase, the impact of PEV car parks on electric distribution systems will be decreased. PEV charging is also minimally affected due to the ability of this idea to balance power without changing the charging rate of each PEV charger. Because of these factors, consumers are expected to offer little resistance to the implementation of this idea in PEV car parks, making it valuable to both car park owners and electric utilities.

\section{Acknowledgements}

The authors would like to thank the members of the Clemson University Electric Power Research Association (CUEPRA) for their financial support and valuable discussion.

\section{References}

[1] Voelcker, J. (2009) How Green Is My Plug-In? IEEE Spectrum, 46, 42-58.

[2] Bunga, S.K. (2013) Impact of Plug in Electric Vehicle Battery Charging on a Distribution System. ProQuest Dissertations and Theses, Ann Arbor, 84. http://search.proquest.com/docview/1356783945

[3] Kisacikoglu, M.C., Ozpineci, B. and Tolbert, L.M. (2010) Examination of a PHEV Bidirectional Charger System for V2G Reactive Power Compensation. 25th Annual IEEE Applied Power Electronics Conference and Exposition (APEC), Palm Springs, 21-25 February 2010, 458-465.

[4] Bosch (2014) Charging Stations. Bosch Electric Vehicle Solutions. http://www.pluginnow.com/charging_stations

[5] Hilshey, A.D., Hines, P.D.H., Rezaei, P. and Dowds, J.R. (2013) Estimating the Impact of Electric Vehicle Smart Charging on Distribution Transformer Aging. IEEE Transactions on Smart Grid, 4, 905-913. http://dx.doi.org/10.1109/TSG.2012.2217385 
[6] Sortomme, E., Hindi, M.M., MacPherson, S.D.J. and Venkata, S.S. (2011) Coordinated Charging of Plug-In Hybrid Electric Vehicles to Minimize Distribution System Losses. IEEE Transactions on Smart Grid, 2, 198-205. http://dx.doi.org/10.1109/TSG.2010.2090913

[7] Pieltain Fernández, L., Román, T.G.S., Cossent, R., Domingo, C.M. and Frías, P. (2011) Assessment of the Impact of Plug-In Electric Vehicles on Distribution Networks. IEEE Transactions on Power Systems, 26, 206-213. http://dx.doi.org/10.1109/TPWRS.2010.2049133

[8] Han, S., Han, S. and Sezaki, K. (2010) Development of an Optimal Vehicle-to-Grid Aggregator for Frequency Regulation. IEEE Transactions on Smart Grid, 1, 65-72. http://dx.doi.org/10.1109/TSG.2010.2045163

[9] Sortomme, E. and El-Sharkawi, M.A. (2012) Optimal Scheduling of Vehicle-to-Grid Energy and Ancillary Services. IEEE Transactions on Smart Grid, 3, 351-359. http://dx.doi.org/10.1109/TSG.2011.2164099

[10] Chindris, M., Cziker, A., Miron, A., Balan, H., Iacob, A. and Sudria, A. (2007) Propagation of Unbalance in Electric Power Systems. 9th International Conference on Electrical Power Quality and Utilisation, Barcelona, 9-11 October 2007, 1-5.

[11] Makram, E., Zambrano, V., Harley, R. and Balda, J. (1989) Three Phase Modeling for Transient Stability of Large Scale Unbalanced Distribution Systems. IEEE Transactions on Power Systems, 4, 487-493. http://dx.doi.org/10.1109/59.193820

[12] Clarke, A. and Makram, E. (2014) An Innovative Approach in Balancing Real Power Using Plug in Hybrid Electric Vehicles. Journal of Power and Energy Engineering, 2, 1-8. http://dx.doi.org/10.4236/jpee.2014.210001

[13] Ko, S.-H., Lee, S.R., Dehbonei, H. and Nayar, C.V. (2006) Application of Voltage- and Current-Controlled Voltage Source Inverters for Distributed Generation Systems. IEEE Transactions on Energy Conversion, 21, 782-792. http://dx.doi.org/10.1109/TEC.2006.877371

[14] Kisacikoglu, M.C., Ozpineci, B. and Tolbert, L.M. (2011) Reactive Power Operation Analysis of a Single-Phase EV/PHEV Bidirectional Battery Charger. IEEE 8th International Conference on Power Electronics and ECCE Asia (ICPE \& ECCE), Jeju, 30 May-3 June 2011, 585-592. http://dx.doi.org/10.1109/ICPE.2011.5944614

[15] Clarke, A., Bihani, H., Makram, E. and Corzine, K. (2013) Fault Analysis on an Unbalanced Distribution System in the Presence of Plug-In Hybrid Electric Vehicles. Clemson Power System Conference. 
Scientific Research Publishing (SCIRP) is one of the largest Open Access journal publishers. It is currently publishing more than 200 open access, online, peer-reviewed journals covering a wide range of academic disciplines. SCIRP serves the worldwide academic communities and contributes to the progress and application of science with its publication.

Other selected journals from SCIRP are listed as below. Submit your manuscript to us via either submit@scirp.org or Online Submission Portal.
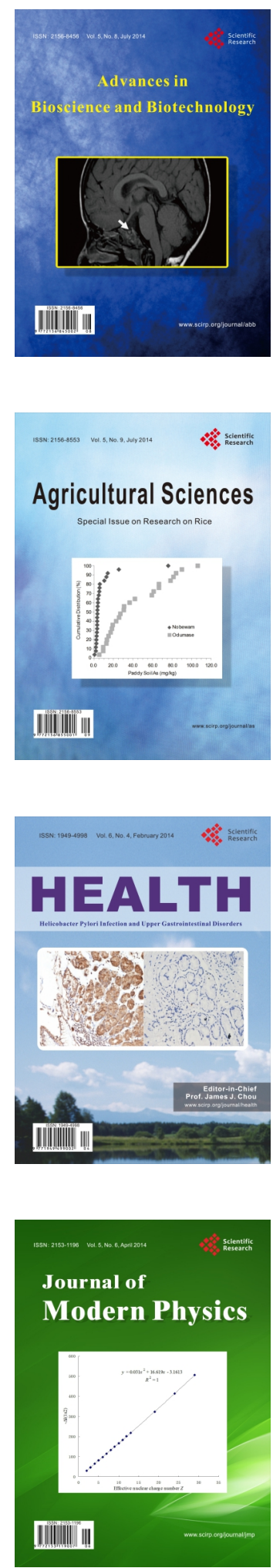
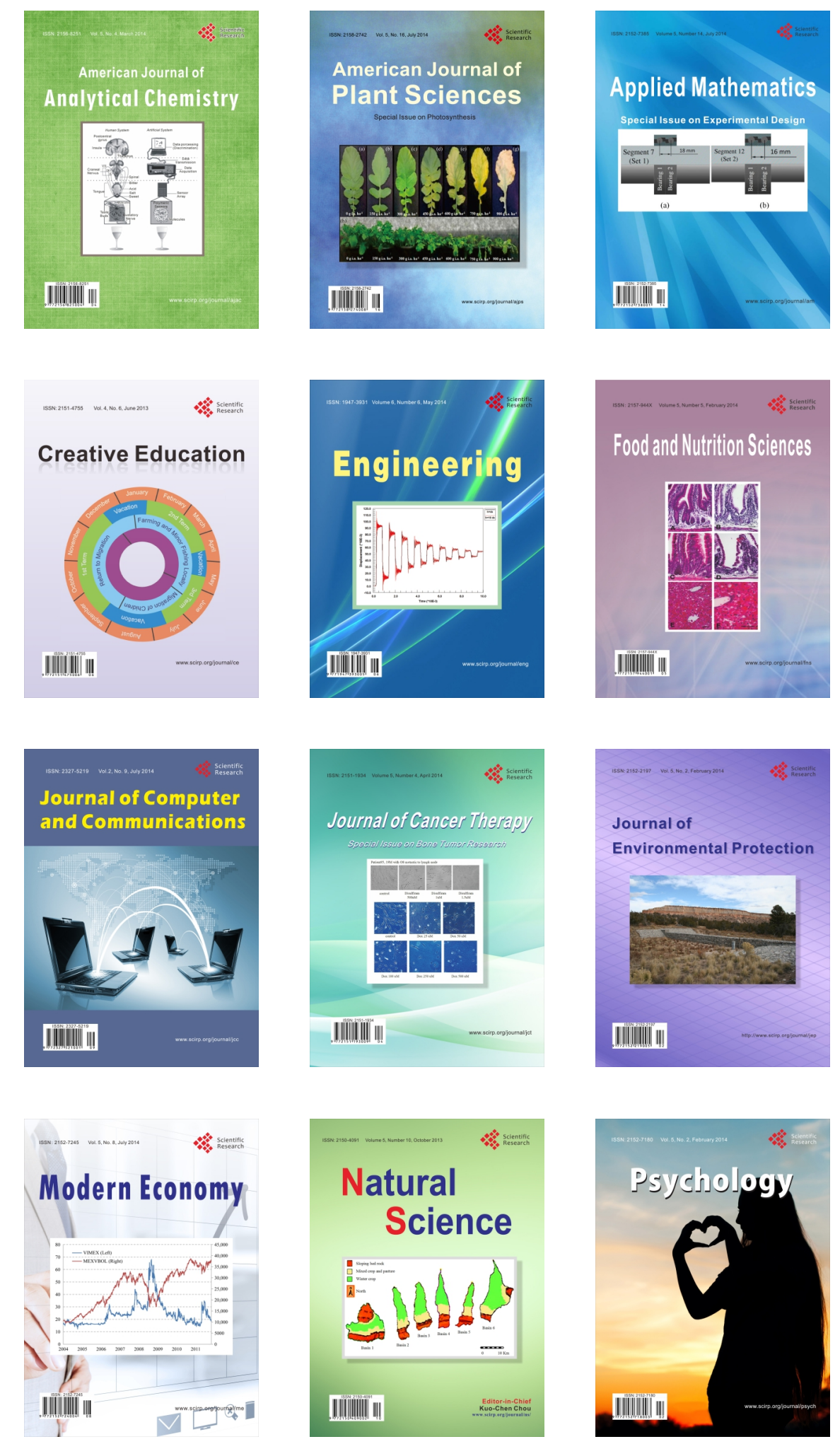